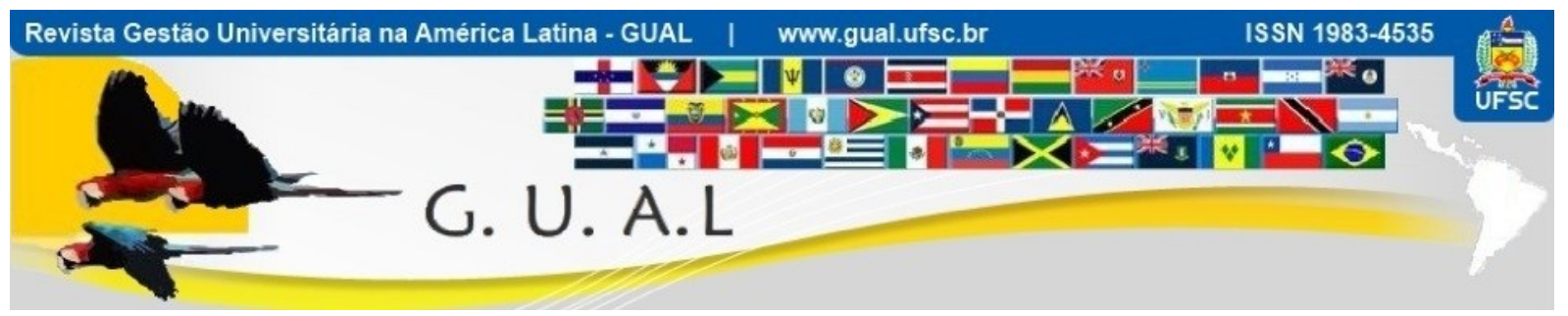

DOI: http://dx.doi.org/10.5007/1983-4535.2012v5n2p36

\title{
RELEVÂNCIA DA ESTRATÉGIA DE COOPETIÇÃO PARA AS IES: O POSICIONAMENTO DO CENTRO UNIVERSITÁRIO CATÓLICO DE SANTA CATARINA
}

\section{COOPETITION STRATEGY RELEVANCE FOR IES: CENTRO UNIVERSITÁRIO CATÓLICO DE SANTA CATARINA STRATEGIC POSITION}

\author{
Jorge Gaio, Bacharel \\ Pontifícia Universidade Católica do Paraná - PUCPR \\ irjorge@marista.org.br \\ Luiz Carlos Duclós, Doutor \\ Pontifícia Universidade Católica do Paraná - PUCPR \\ delmarciomoura@ufpi.edu.br
}

Hélio Gilberto Amaral, Doutor Pontifícia Universidade Católica do Paraná - PUCPR eulaliocampelo@ufpi.edu.br

Recebido em 30/outubro/2011

Aprovado em 03/julho/2012

Sistema de Avaliação: Double Blind Review

Esta obra está sob uma Licença Creative Commons Atribuição-Uso. 


\title{
RESUMO
}

A concorrência dos consolidadores de mercado na área educacional tem se intensificado no cenário nacional e em mercados regionais, como no caso do Estado de Santa Catarina, pressionando as IES de pequeno e médio porte a estabelecerem estratégias de competição, de cooperação e de coopetição. O objetivo deste position paper é apresentar de maneira estruturada as estratégias de excelência dos serviços prestados (KANO, 1984) e as estratégias de coopetição (NALEBUFF; BRANDENBURGER, 1996; DAGNINO; PADULA, 2002) utilizadas pelo Centro Universitário Católico de Santa Catarina, desde 2009, por ocasião da entrada no mercado de Joinville. A revisão da literatura contemplou as principais estratégias de competição, cooperação e coopetição, bem como a matriz de Kano (1984). Foram apresentadas as estratégias mais relevantes decorrentes do modelo de Kano (1984) e as estratégias de coopetição utilizadas pelo Centro Universitário Católico de Santa Catarina. Os resultados obtidos nesta pesquisa sinalizam que o posicionamento estratégico visa à coopetição entre os atores do ensino superior da região, apesar de apresentar um conjunto de estratégias diferenciadas dessa tendência, em seu posicionamento de entrada inicial.

Palavras-chave: Posicionamento estratégico. Matriz de Kano. Coopetição. Instituições de Ensino Superior.

\begin{abstract}
The competition from consolidators in the educational market has intensified in the national and regional markets, such as Santa Catarina State, pressing the small and medium size IES to establish strategies of competition, cooperation and coopetition. The purpose of this position paper is to present the structured strategies for service excellence (KANO, 1984) and strategies coopetition (BRANDENBURGER and NALEBUFF, 1996; DAGNINO; PADULA, 2002) used by Centro Universitário Católico de Santa Catarina, established in Joinville since 2009. The literature review covered the main strategies of competition, cooperation, coopetition and the Kano (1984) matrix. It was presented the most relevant strategies under the Kano (1984) model and the coopetition strategies used by Centro Universitário Católico de Santa Catarina. The results of this research indicate the coopetition strategic position between the actors involved in higher education in the region, despite having a different set of strategies in its entrance position.
\end{abstract}

Key words: Strategic position. Kano’s Matrix. Coopetition. IES. 


\section{INTRODUÇÃO}

As alterações no cenário socioeconômico brasileiro neste princípio de século têm tido um importante impacto no setor da educação - em especial, no ensino superior privado. $\mathrm{O}$ aumento da oferta de vagas, que limita o acesso a processos seletivos brandos e ao financiamento dos estudos, bem como o aumento percentual de alunos das classes C e D no número de matrículas, associados ao crescimento dos grandes grupos educacionais, também chamados de consolidadores de mercado, alteraram significativamente a situação das Instituições de Ensino Superior (IES) privadas no país.

O Estado de Santa Catarina possui uma dispersão geográfica relativamente homogênea, sendo composto de pequenas e médias cidades. Isso é acompanhado por uma dispersão das IES por todo o estado, boa parte delas comunitárias. Santa Catarina tem também a maior média de jovens entre 17 e 25 anos cursando o ensino superior no Brasil. Nesse cenário, a instituição comunitária Centro Universitário Católico de Santa Catarina foi implantada com o objetivo de oferecer uma alternativa de ensino alicerçada em valores humanísticos e com uma marca reconhecida internacionalmente, para contribuir com as instituições já existentes. Assim, este artigo discute uma estratégia de coopetição na implantação do Centro Universitário Católico de Santa Catarina.

\section{O ENSINO SUPERIOR PRIVADO}

Conhecer os cenários das IES privadas no Brasil e no Estado de Santa Catarina nos ajuda a compreender o impacto da concorrência no contexto nacional e regional para o Centro Universitário Católico de Santa Catarina. É este, portanto, o foco desta seção.

\subsection{O cenário das IES privadas no Brasil}

O crescimento do número de vagas no ensino superior privado do Brasil tem aumentado significativamente nos últimos anos. Partindo do início do século XX, em que o ensino superior era altamente restrito e as elites econômicas mandavam seus filhos para estudar no exterior, chegamos ao final desse século com uma restrição de oferta, traduzida pelos processos de seleção dos melhores alunos, os vestibulares, que determinavam a possibilidade ou não de uma pessoa ingressar no ensino superior. As fases pelas quais o ensino superior privado do Brasil passou nos últimos anos podem ser resumidas, de forma simplificada, na tabela 1 . 


\section{RELEVÂNCIA DA ESTRATÉGIA DE COOPETIÇÃO PARA AS IES: O POSICIONAMENTO DO \\ CENTRO UNIVERSITÁRIO CATÓLICO DE SANTA CATARINA \\ DOI: http://dx.doi.org/10.5007/1983-4535.2012v5n2p36}

Tabela 1 Fases do ensino superior privado no Brasil

\begin{tabular}{|c|c|c|}
\hline Período & Desafios & Diferenciais \\
\hline De 1980 a 1996 & Conseguir autorizar cursos & $\begin{array}{c}\text { Força política e porte (devido à reserva de } \\
\text { mercado e ao ganho com a inflação) }\end{array}$ \\
\hline De 1996 a 2003 & $\begin{array}{c}\text { Construir prédios, abrir novas } \\
\text { unidades, ampliar cursos }\end{array}$ & $\begin{array}{c}\text { Velocidade, capital (recursos financeiros), } \\
\text { oportunismo }\end{array}$ \\
\hline De 2003 a 2008 & $\begin{array}{c}\text { Adaptar-se aos novos mecanismos } \\
\text { regulatórios }\end{array}$ & Gestão da burocracia governamental \\
\hline De 2001 a 2010 & $\begin{array}{c}\text { Aprimorar a gestão da atividade meio } \\
\text { (administrativo, financeiro, marketing, } \\
\text { RH etc.) }\end{array}$ & Gestão profissionalizada \\
\hline
\end{tabular}

Fonte: Hoper Group (2010, p. 3).

Por sua vez, o início do século XXI apresenta um expressivo aumento no número de vagas disponíveis, como pode ser visto no gráfico 1, passando de 516.663 vagas em 2001 para 2.985.137 vagas em 2008, segundo os dados do Instituto Nacional de Estudos e Pesquisas Educacionais Anísio Teixeira (INEP). O aumento de vagas não foi seguido por um aumento proporcional no número de alunos. $\mathrm{Na}$ realidade, como mostra o gráfico 1 , o número de alunos ingressantes tem mostrado uma tendência de estabilização nos últimos anos, ao passo que o número de vagas ofertadas continua crescendo.

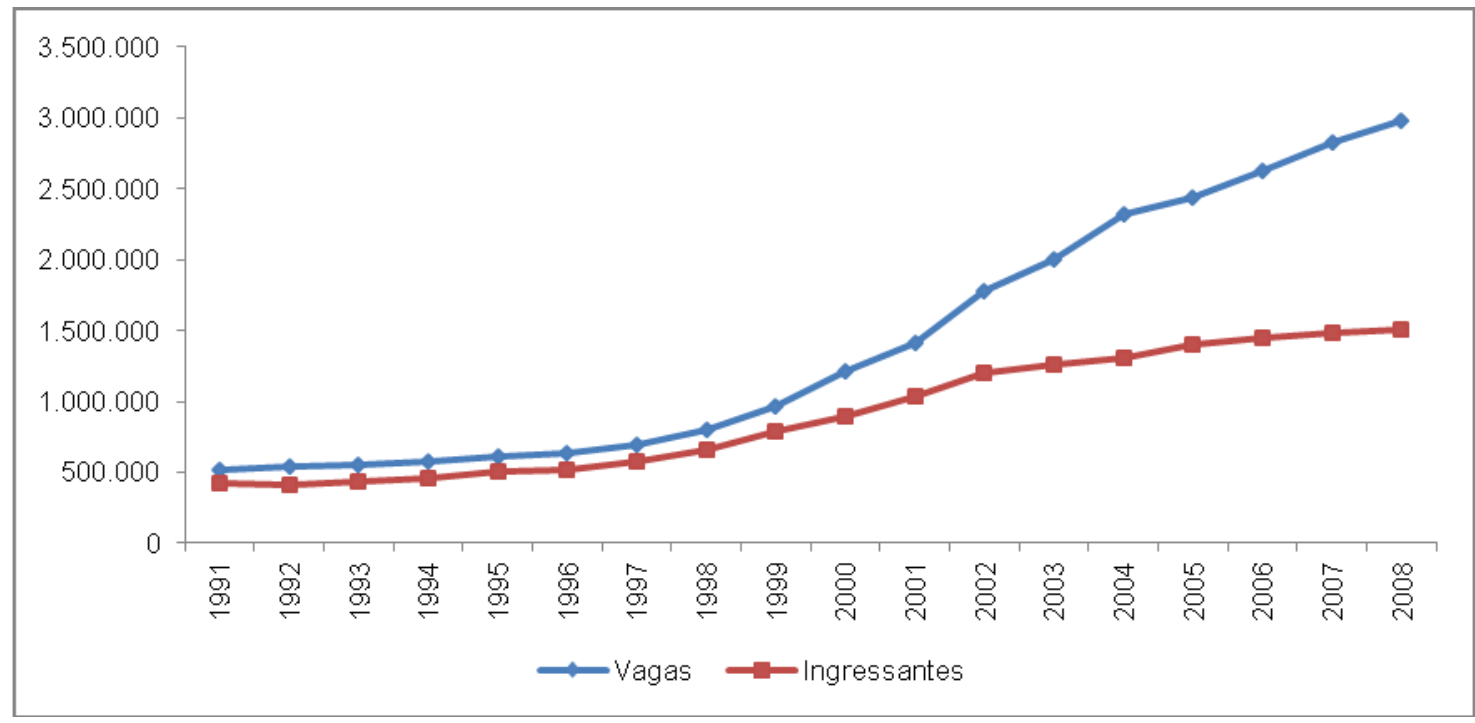

Gráfico 1 Evolução do número de vagas e de ingressantes no ensino superior brasileiro Fonte: INEP (2009, p. 37).

Essa ampliação de oferta é devida, em parte, à entrada de grandes grupos econômicos no setor da educação. Os 16 maiores grupos educacionais privados do Brasil, mostrados na tabela 2, ocupam aproximadamente um quarto das matrículas, apresentando uma tendência de aumento desse percentual. 


\section{RELEVÂNCIA DA ESTRATÉGIA DE COOPETIÇÃO PARA AS IES: O POSICIONAMENTO DO CENTRO UNIVERSITÁRIO CATÓLICO DE SANTA CATARINA \\ DOI: http://dx.doi.org/10.5007/1983-4535.2012v5n2p36}

Tabela 2 Maiores grupos educacionais privados do Brasil

\begin{tabular}{|c|c|c|c|c|c|}
\hline Posição & $\begin{array}{c}\text { Grupo } \\
\text { educacional }\end{array}$ & $\begin{array}{l}\text { Receita líquida } \\
\text { no ano de } 2009 \\
\text { (milhões de } R \$ \text { ) }\end{array}$ & $\begin{array}{l}\text { Participação na } \\
\text { receita do setor }\end{array}$ & $\begin{array}{l}\text { Número de alunos } \\
\text { na graduação } \\
\text { presencial em } 2009\end{array}$ & $\begin{array}{l}\text { Participação } \\
\text { no mercado }\end{array}$ \\
\hline 1 & Estácio de Sá & 1.009 & $4,1 \%$ & 187.000 & $4,7 \%$ \\
\hline 2 & UNIP & 923 & $3,7 \%$ & 166.000 & $4,2 \%$ \\
\hline 3 & Anhanguera & 904 & $3,7 \%$ & 148.000 & $3,8 \%$ \\
\hline 4 & Kroton/Iuni & 612 & $2,5 \%$ & 86.000 & $2,2 \%$ \\
\hline 5 & Laureate & 538 & $2,2 \%$ & 73.000 & $1,9 \%$ \\
\hline 6 & Uninove & 428 & $1,7 \%$ & 97.000 & $2,5 \%$ \\
\hline 7 & SEBSA & 384 & $1,6 \%$ & 9.092 & $0,2 \%$ \\
\hline 8 & Universo & 265 & $1,1 \%$ & 47.000 & $1,2 \%$ \\
\hline 9 & $\begin{array}{c}\text { Ânima } \\
\text { Educação }\end{array}$ & 254 & $1,0 \%$ & 36.000 & $0,9 \%$ \\
\hline 10 & Uniban & 247 & $1,0 \%$ & 55.000 & $1,4 \%$ \\
\hline 11 & Unicsul & 218 & $0,9 \%$ & 27.000 & $0,7 \%$ \\
\hline 12 & Grupo Ibmec & 143 & $0,6 \%$ & 12.000 & $0,3 \%$ \\
\hline 13 & $\begin{array}{c}\text { Maurício de } \\
\text { Nassau }\end{array}$ & 137 & $0,6 \%$ & 26.000 & $0,7 \%$ \\
\hline 14 & $\begin{array}{c}\text { UB } \\
\text { Participações }\end{array}$ & 109 & $0,4 \%$ & 17.000 & $0,4 \%$ \\
\hline 15 & Unit & 106 & $0,4 \%$ & 21.000 & $0,5 \%$ \\
\hline 16 & Fanor/Devry & 80 & $0,3 \%$ & 12.000 & $0,3 \%$ \\
\hline \multicolumn{2}{|c|}{ Subtotal } & 6.357 & $25,8 \%$ & 1.019 .092 & $25,9 \%$ \\
\hline \multicolumn{2}{|c|}{ Total do setor privado } & 24.700 & - & 3.940 .000 & - \\
\hline
\end{tabular}

Fonte: Hoper Group (2010, p. 23).

Apesar do esforço do governo no sentido de aumentar as vagas nas IES públicas, o aumento de vagas tem sido preponderantemente do setor privado, como mostra o gráfico 2 .

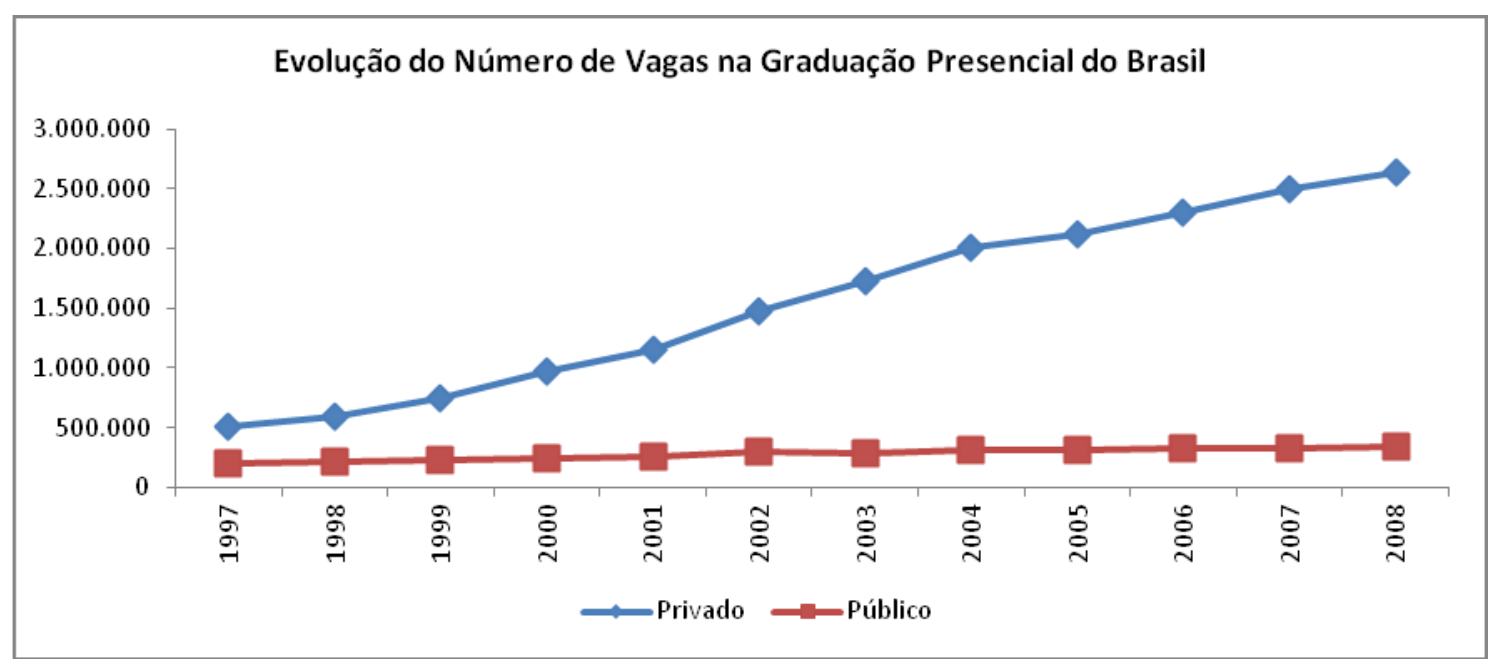

Gráfico 2 Evolução do número de vagas na graduação presencial do Brasil Fonte: Hoper Group (2010, p. 4). 


\section{RELEVÂNCIA DA ESTRATÉGIA DE COOPETIÇÃO PARA AS IES: O POSICIONAMENTO DO CENTRO UNIVERSITÁRIO CATÓLICO DE SANTA CATARINA DOI: http://dx.doi.org/10.5007/1983-4535.2012v5n2p36}

Dessa maneira, não tendo o aumento no número de matrículas acompanhado o aumento da oferta de vagas - chegando em 2009, à média de 0,5 matrículas por vaga ofertada e com esse número ainda em tendência de queda -, o ticket médio do ensino superior privado está em permanente declínio nos últimos anos, como mostra o gráfico 3.

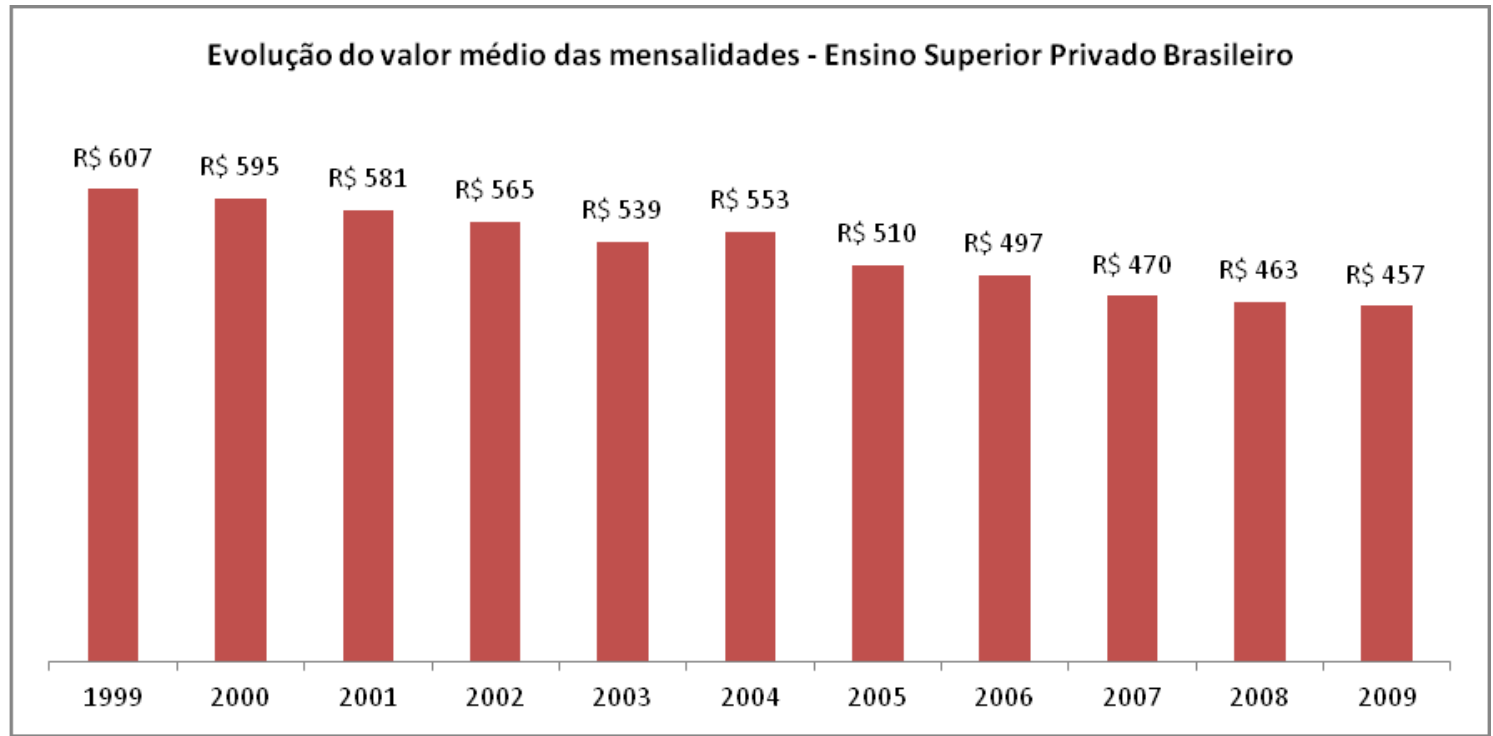

Gráfico 3 Evolução do valor médio das mensalidades no ensino superior privado brasileiro Fonte: Hoper Group (2010, p. 8).

Dos sete estados da Federação que apresentam ticket médio abaixo dos $\mathrm{R} \$ 400$, seis deles concentram-se nas regiões brasileiras do Norte e Nordeste, como mostra a tabela 3.

Tabela 3 Mensalidade média dos estados brasileiros

\begin{tabular}{|c|c|c|}
\hline Posição & UF & Mensalidade média \\
\hline 1 & Rio Grande do Sul & $\mathrm{R} \$ 720,76$ \\
\hline 2 & Minas Gerais & $\mathrm{R} \$ 641,83$ \\
\hline 3 & Distrito Federal & $\mathrm{R} \$ 622,27$ \\
\hline 4 & Santa Catarina & $\mathrm{R} \$ 541,10$ \\
\hline 5 & Bahia & $\mathrm{R} \$ 538,50$ \\
\hline 6 & Paraná & $\mathrm{R} \$ 536,86$ \\
\hline 7 & Pará & $\mathrm{R} \$ 536,79$ \\
\hline 8 & Goiás & $\mathrm{R} \$ 533,57$ \\
\hline 9 & Mato Grosso do Sul & $\mathrm{R} \$ 496,81$ \\
\hline 10 & Amazonas & $\mathrm{R} \$ 476,24$ \\
\hline 11 & Paraíba & $\mathrm{R} \$ 463,07$ \\
\hline 12 & Pernambuco & $\mathrm{R} \$ 462,65$ \\
\hline 13 & Rondônia & $\mathrm{R} \$ 462,55$ \\
\hline 14 & Mato Grosso & $\mathrm{R} \$ 454,31$ \\
\hline 15 & Maranhão & $\mathrm{R} \$ 432,38$ \\
\hline
\end{tabular}




\begin{tabular}{|l|c|c|}
16 & Acre & $\mathrm{R} \$ 431,78$ \\
\hline 17 & Espírito Santo & $\mathrm{R} \$ 430,97$ \\
\hline 18 & Ceará & $\mathrm{R} \$ 424,15$ \\
\hline 19 & Amapá & $\mathrm{R} \$ 419,81$ \\
\hline 20 & Rio de Janeiro & $\mathrm{R} \$ 416,44$ \\
\hline 21 & São Paulo & $\mathrm{R} \$ 373,38$ \\
\hline 22 & Roraima & $\mathrm{R} \$ 365,62$ \\
\hline 23 & Rio Grande do Norte & $\mathrm{R} \$ 363,18$ \\
\hline 24 & Sergipe & $\mathrm{R} \$ 342,43$ \\
\hline 25 & Piauí & $\mathrm{R} \$ 324,65$ \\
\hline 26 & Alagoas & $\mathrm{R} \$ 306,34$ \\
\hline 27 & Tocantins & $\mathrm{R} \$ 286,20$ \\
\hline
\end{tabular}

Fonte: Hoper Group (2010, p. 15).

Dessa forma, com o aumento da competição pelos alunos e com a queda dos preços das mensalidades, as IES privadas estão sendo compelidas a mostrar um aumento de eficiência e uma redução de custos para poderem sobreviver. No caso dos grandes grupos educacionais, esse aumento de eficiência vem tendo dois fortes propulsores. O primeiro é o ganho de escala que centenas de milhares de alunos podem dar para um sistema. O outro é o orçamento cruzado, em que o gestor de cada unidade tem metas de custeio, investimento, lucros antes de juros, impostos, depreciação e amortização (Ebitda), entre outras.

No caso das IES de médio e pequeno porte, as quedas do valor médio das mensalidades e a diminuição do número de alunos em alguns cursos têm que ser compensadas com ganhos de eficiência. A estratégia de coopetição se apresenta como uma alternativa viável para a redução de custos e ganhos de escala em processos interinstitucionais. Desde atividades de back office até projetos conjuntos, como o Inovaparque, em Joinville, os ganhos advindos da coopetição são significativos para todos os participantes.

\subsection{O cenário das IES privadas no Estado de Santa Catarina}

O Estado de Santa Catarina possui um índice de 17\% da população de 17 a 25 anos matriculada em IES. Uma das razões dessa liderança em relação aos outros estados da Federação certamente se deve ao sistema de IES comunitárias criado por alguns municípios que compõem a Associação Catarinense de Fundações Educacionais (ACAFE), conforme o censo da Secretaria de Estado da Educação (2010).

Se por um lado o Estado de Santa Catarina não possui cidades com mais de 600 mil habitantes, o que pulveriza mais o público-alvo, por outro, o valor médio das mensalidades de 
R \$ 541,10 é elevado, situando-se entre as maiores médias do Brasil, conforme mostra a tabela 3. Acrescentando-se a isso os aspectos culturais decorrentes da colonização iminentemente europeia realizada no estado, criou-se um ambiente altamente propício à coopetição.

Em especial, o norte-nordeste do estado tem um conjunto de indústrias voltadas tanto para o mercado nacional quanto para exportação, o que gera não somente um volume grande de entrada de recursos na região, mas também uma demanda, em grande quantidade, de mão de obra especializada. Tais características se refletem em uma demanda e, em muitos casos, no apoio dessas empresas para a formação de profissionais, muitas vezes com bolsas de estudo das próprias empresas.

\section{FUNDAMENTAÇÃO TEÓRICA}

Alguns conceitos e elementos-chave sobre estratégia, estratégia competitiva, estratégia cooperativa, estratégia coopetitiva e o modelo de qualidade em serviços de Kano (1984) são apresentados nesta seção, de modo a fundamentar o posicionamento estratégico do Centro Universitário Católico de Santa Catarina, objeto deste estudo.

\subsection{Estratégia}

Andrews (1996, p. 17) define a estratégia como "o modelo de decisões de uma empresa que determina e revela seus objetivos, propósitos ou metas, produz as principais políticas e planos para atingir essas metas e define o escopo de negócios que a empresa vai adotar”. Estratégia é, assim, um conjunto de ações que mobiliza recursos em um ambiente determinado, visando construir um futuro desejado. Para esse autor, a estratégia competitiva está no nível da unidade de negócio, e as estratégias funcionais são formadas pelas áreas de apoio.

Para Prahalad e Hamel (1996), a estratégia é um esforço criativo para imaginar o futuro da organização, proveniente do aprendizado coletivo e das competências essenciais que causarão maior impacto em termos de valor percebido pelo cliente. A estratégia passa a ser um aprendizado construído ao longo do tempo, visando explorar oportunidades novas para a organização.

Mintzberg e Waters (1996) afirmam que a complexidade e a imprevisibilidade incontrolável do ambiente são as principais fontes para o surgimento de estratégias não intencionadas na organização, pois a capacidade racional do homem é limitada, ou seja, este 


\section{RELEVÂNCIA DA ESTRATÉGIA DE COOPETIÇÃO PARA AS IES: O POSICIONAMENTO DO CENTRO UNIVERSITÁRIO CATÓLICO DE SANTA CATARINA DOI: http://dx.doi.org/10.5007/1983-4535.2012v5n2p36}

não pode prever todas as nuances do ambiente, sejam elas internas ou externas. A organização pode experimentar diferentes situações a fim de descobrir qual irá ser bem-sucedida. Portanto, é no fazer estratégico que emergem estratégias pertinentes e que se atribuem significados retrospectivos, afetando assim a estrutura.

Gomez (2010) enfatiza que a estratégia não é algo que uma empresa tem, mas algo que faz, ou, mais exatamente, algo para que seus agentes façam um fluxo contínuo de inúmeras ações, decisões e posições tomadas por um grande número de agentes. Abrange, portanto, todas as ações da organização.

Bourdieu (1996) salienta que as estratégias podem ser entendidas como as sequências de práticas estruturadas ou as séries de ações ordenadas e orientadas que os agentes desenvolvem em função de um habitus adquirido e das possibilidades que um determinado campo oferece para a obtenção e maximização dos lucros específicos no campo em questão. As estratégias são, portanto, ações que visam a determinadas finalidades sem serem necessariamente concebidas como tais.

\subsection{Estratégia competitiva}

Usualmente, no mundo empresarial, a competição é vista como um processo estratégico de tomada de decisão frente aos ambientes diversos. Este é o instrumento usado pelas empresas para buscar um resultado superior. Os atores que trabalham em determinado setor buscam ocupar posições privilegiadas de mercado (PORTER, 1999), incrementar os recursos, as capacidades organizacionais (BARNEY, 1991) e as competências essenciais (PRAHALAD; HAMEL, 1996), visando à criação de valor. A rivalidade entre as organizações se acentua em virtude das diferenças de recursos, capacidades e competências existentes, além de decorrer do próprio ambiente.

Porter (1999, p. 33) enfatiza que a estratégia competitiva "é criar uma posição exclusiva e valiosa, envolvendo um diferente conjunto de atividades"; "significa escolher deliberadamente um conjunto diferente de atividades em relação aos concorrentes para fornecer um mix único de valor". Esse autor ainda destaca que a estratégia não é apenas o que a organização pretende fazer, mas também o que ela não precisa fazer. Portanto, a estratégia competitiva é a maneira como se irá competir em um determinado mercado. A estratégia está intimamente ligada à criação de valor para os acionistas, clientes e demais stakeholders. No ambiente competitivo, as organizações são chamadas a se transformarem e a se adaptarem às 


\section{RELEVÂNCIA DA ESTRATÉGIA DE COOPETIĈ̃O PARA AS IES: O POSICIONAMENTO DO CENTRO UNIVERSITÁRIO CATÓLICO DE SANTA CATARINA DOI: http://dx.doi.org/10.5007/1983-4535.2012v5n2p36}

necessidades do mercado. Isso se torna possível quando há alinhamento entre as atividades internas e a proposição de valor para as partes interessadas.

Segundo Dagnino e Padula (2002), a estratégia competitiva envolve a relação da organização com seu meio - de modo especial, com o setor em que ela compete. Assim, as decisões de uma empresa provocam reações nos competidores, levando imediatamente a mudanças nas estratégias adotadas, o que desencadeia o jogo competitivo de resultado de "soma zero", em que um ganha e os outros perdem, ou o de "soma não zero", em que todos perdem. Nessa estratégia competitiva, as empresas buscam interesses isolados e individuais por meio de benefícios próprios sobre seus concorrentes.

Para Hitt, Ireland e Hoskisson (2002, p. 189), a dinâmica competitiva "resulta de uma série de ações e respostas competitivas entre firmas que concorrem dentro de uma indústria particular”. Lengler e Rathmann (2006, p. 55) se coadunam com essa posição, afirmando que a estratégia competitiva provoca atos de ação e reação entre as empresas. Isso se vê, por exemplo, quando do lançamento de um novo produto por uma empresa, em que a outra imita ou esboça uma ação reativa.

Sinteticamente, a estratégia competitiva compreende a maximização dos ganhos individuais, a assimetria das estratégias empregadas e a intensidade acirrada da competição entre os agentes, com intuito de obter-se desempenho superior ao dos concorrentes.

\subsection{Estratégia de cooperação}

Para Gray e Wood (1991), a cooperação são redes de colaboração entre empresas com o intuito de minimizar os problemas advindos da turbulência de mercado. As organizações podem conviver num mesmo contexto, cooperando racionalmente a fim de alcançarem objetivos comuns. Essa é uma estratégia que exige confiança entre os participantes, para que realizem a estratégia de forma combinada.

Segundo Nalebuff e Brandenburger (1996), a ação cooperativa entre empresas não significa a ausência de concorrência. A atuação conjunta gera maior inovação, sinergia e desempenho do que isoladamente; quando isso não ocorre, as empresas são expostas a um alto risco da estagnação. As oportunidades de cooperação fomentam projetos ou novos negócios.

Para Dagnino e Padula (2002), a cooperação trabalha com a interdependência das empresas, em que todos podem ganhar, uma vez que compartilham expertises essenciais, constituindo-se assim um jogo de soma positiva. Segundo Leão (2005), as regras são 


\section{RELEVÂNCIA DA ESTRATÉGIA DE COOPETIÇÃO PARA AS IES: O POSICIONAMENTO DO CENTRO UNIVERSITÁRIO CATÓLICO DE SANTA CATARINA DOI: http://dx.doi.org/10.5007/1983-4535.2012v5n2p36}

informais e disseminadas, sendo que cada um define seus objetivos isolados. Assim, ao se agir para maximizar interesses próprios, que são similares, se desenvolve uma relação de competição que se configura num jogo de soma zero.

Segundo Kanter (1996), a formação de redes comuns é denominada "alianças estratégicas". Estas favorecem o compartilhamento de recursos escassos e possibilitam que as empresas atendam às premissas de inovação contínua, de modo a ampliarem suas competências. Para Nalebuff e Brandenburger (1996), a estratégia de cooperação é comumente usada para se estabelecer uma parceria com uma organização, a fim de se desbancar uma terceira. Kanter (1996) identifica três categorias de parcerias: i) alianças de serviços multiorganizacionais, por meio de consórcio de empresas; ii) alianças oportunistas, via joint ventures; iii) alianças entre os envolvidos na cadeia de valor. Tais acordos de parceria são caracterizados pela independência e pela complementaridade de recursos físicos e humanos.

Lengler e Rathmann (2006, p. 55) acrescentam que ficam evidentes os objetivos comuns entre os envolvidos na atuação cooperativa. Essa postura permite uma ação conjunta, em que se reforçam as capacidades individuais, a fim de desenvolverem-se novos produtos, adentrar-se em novos mercados, reduzirem-se custos, dividirem-se riscos, promover-se capacitação, desenvolverem-se novas tecnologias. Fica evidenciado, assim, que o ganho obtido pela cooperação é resultado do trabalho conjunto.

Agostinho (2003) trata dos sistemas complexos adaptativos, sendo que uma das propriedades básicas abordada é a cooperação entre os membros do sistema, fortalecendo a inovação e servindo como alicerce para o desenvolvimento. A cooperação se torna uma estratégia eficiente de novos competidores acessarem novos mercados e tecnologias.

Para Mintzberg, Ahlstrand e Lampel (2000, p. 188), as redes de relacionamentos cooperativas oportunizam a formação de estratégia em que:

deixa os limites exclusivos da organização isolada e torna-se um processo conjunto, para ser desenvolvido com parceiros. A empresa negocia, através de uma rede de relacionamentos, formular uma estratégia coletiva. Há nitidamente partes de planejamento e posicionamento nessa formulação, mas como veremos, o poder e, em especial, os aspectos negociados da estratégia são grandes.

A estratégia cooperativa, segundo Kanter (1996), depende do envolvimento colaborativo e da confiança mútua. Esses princípios são necessários para que, ao se definirem 
os objetivos da cooperação, se consigam estabelecer com fluidez as relações entre os atores envolvidos, a fim de gerar-se a aprendizagem estratégica e o alcance dos objetivos desenhados a priori. Tais acordos podem ser operacionalizados por meio de acordos formais ou informais.

Segundo Verschoore e Balestrin (2006), as redes de cooperação apresentam cinco fatores competitivos: ganhos de escala e poder de mercado; acesso a um conjunto de soluções; aprendizagem e inovação; redução e custos e riscos; capital social e de confiança entre os membros das organizações. Tais elementos oportunizam desempenho superior de pequenas e médias organizações frente ao acirramento da concorrência do mundo globalizado.

Porter (1999) expõe que a cooperação entre organizações deve ser utilizada de maneira seletiva, temporária e em projetos que não envolvam atividades centrais do core business da organização e que não as conectem às suas fontes de vantagem competitiva. Hamel (1991) corrobora essa posição, afirmando que a colaboração competitiva pode ser uma forma de as empresas adquirirem habilidades dos parceiros; daí a necessidade matura do escopo, descrevendo o real delineamento da parceria.

\subsection{Estratégia de coopetição}

Segundo Nalebuff e Brandenburger (1996), quando a competição e a cooperação acontecem ao mesmo tempo, ocorre a coopetição, estabelecendo-se parceiras por um determinado período de tempo e com o suporte da Teoria dos Jogos. Para isso, as empresas devem identificar em suas cadeias produtivas os processos vantajosos para praticarem o "ganha-ganha", ou o efficience consumer response. A estratégia consiste num relacionamento parcialmente orgânico entre empresas concorrentes, no qual todos, em geral, ganham.

Segundo Nalebuff e Brandenburger (1996), a Teoria dos Jogos auxilia os gestores a agirem de maneira racional para a tomada de decisão, considerando o ambiente, os diversos stakeholders e as interações, por meio de um conjunto de ferramentas. Portanto, os gestores/jogadores adotam jogadas conforme a posição e reação dos outros jogadores. Para Merofa e Bueno (2009, p. 2), as ações tomadas podem abranger comportamentos competitivos e/ou cooperativos, dependendo do ambiente e dos objetivos dos atores que fazem parte do jogo. 


\section{RELEVÂNCIA DA ESTRATÉGIA DE COOPETIÇÃO PARA AS IES: O POSICIONAMENTO DO CENTRO UNIVERSITÁRIO CATÓLICO DE SANTA CATARINA DOI: http://dx.doi.org/10.5007/1983-4535.2012v5n2p36}

Segundo Lengler e Rathmann (2006, p. 56), para que a coopetição funcione, a cooperação e a competição devem ser minimizadas, atuando com menor rivalidade e com colaboração em menores proporções.

Para Gollo (2006, p. 6), alguns são os motivos que levam as organizações a desenvolverem estratégias coopetitivas: acirrada competição; rápidas mudanças tecnológicas; necessidade de obter recursos e serviços complementares; bem como adquirir e compartilhar conhecimentos, aprendizagem organizacional e habilidades, sobrepor barreiras à entrada, aumentar o poder de compra, acessar novos mercados, disponibilizar serviços de qualidade no ensino superior e estabelecer foco no core business. Tais arranjos possibilitam que as organizações conquistem mais valor e desenvolvam novas oportunidades estratégicas.

Para Leão (2005), a coopetição estabelece uma forte troca de informação e conhecimento, podendo se configurar numa relação formal ou informal. Nesse sentido, as regras e acordos formais são estipulados para se alcançar o equilíbrio da relação e reduziremse os conflitos. Os concorrentes formulam objetivos comuns e desenvolvem uma relação de proximidade.

Para Dagnino e Padula (2002), a dinâmica da coopetição é estabelecida pela interdependência criada entre as empresas como fonte de criação de valor, porque estas geram benefícios mútuos que não alcançariam individualmente, mas não equivalentes. Nesse sentido, para Martinelli e Sparks (2003), a coopetição é um relacionamento sinérgico e balanceado entre empresas concorrentes, fundamentado na presença de benefícios mútuos, embora seja difícil identificar se o desempenho de fato decorre da aliança estabelecida.

Para Dotto e Wittmann (2006, p. 62), é comum encontrar a coopetição entre organizações em

arranjos produtivos locais, sistemas locais de produção em redes de empresas, onde se processam formas de governança que estimulam o compartilhamento de ações que permitem uma maior sinergia entre os membros e, por conseguinte, aumentos de competitividade do grupo de empresas, embora possam estar atuando em mercados similares.

A estratégia não pode existir sem se considerar como, de maneira recíproca, a empresa afeta seus concorrentes e é por eles afetada. Portanto, para Lado, Boyd e Hanlon (1997), a coexistência das estratégias de competição e cooperação e o equilíbrio entre elas se mostram vitais para a obtenção de resultados superiores e para a sobrevivência das empresas nos 


\section{RELEVÂNCIA DA ESTRATÉGIA DE COOPETIĈ̃O PARA AS IES: O POSICIONAMENTO DO CENTRO UNIVERSITÁRIO CATÓLICO DE SANTA CATARINA DOI: http://dx.doi.org/10.5007/1983-4535.2012v5n2p36}

mercados. Esse equilíbrio facilita o compartilhamento e a combinação de recursos estratégicos e conhecimento, os quais são capazes de gerar vantagens competitivas.

Segundo Quint (1997, p. 7), coopetição refere-se a estratégias de negócio em que empresas rivais, normalmente concorrentes para um mercado, se acertam de modo a criar um produto ou indústria forte. O raciocínio que suporta a coopetição é que, se as empresas só enxergarem o mundo em um "ganha-perde" ou em um quadro competitivo de referência, elas bloquearão a possibilidade do "ganha-ganha" ou de vantagens cooperativas. Uma estratégia de competir em algumas arenas, mas com a cooperação em outras, oferece a oportunidade de se colherem os benefícios que o mercado pode oferecer às duas estratégias.

A coopetição, segundo Nalebuff e Brandenburger (1996), está pautada na Teoria dos Jogos, em que o negócio é um jogo no qual as organizações estão ora cooperando, ora competindo com outras organizações em seu setor. Nesse caso, a visão coopetitiva direcionase para a estrutura do jogo positiva, mas variável, com objetivos parcialmente congruentes. As organizações passam a compartilhar informações, riscos, competências e recompensas. Criar um relacionamento coopetitivo é uma maneira eficiente de se realizarem alianças estratégicas.

Para Nalebuff e Brandenburger (1996) e Martinelli e Sparks (2003), a coopetição traz alguns benefícios para as organizações: estas realizam atividades em conjunto, aprimoram a competitividade, conquistam a liderança de mercado e combinam cooperação e competição. $\mathrm{O}$ compartilhamento mútuo entre organizações cria vantagem competitiva, um elemento-chave para se mensurar a temporalidade da aliança.

Bengtsson e Kock (1999 apud LEÃO, 2005, p. 6), identificam três proposições referentes ao comportamento coopetitivo: a heterogeneidade dos recursos entre organizações; a combinação dos aspectos da competição e da cooperação; o fato de que, quanto mais próximas ao cliente, mais as empresas tendem a competir e, quanto mais distantes, mais tendem a cooperar. Para Leão (2005, p. 7), o último comportamento não é percebido quando pequenas e médias organizações somam esforços para a comercialização de produtos ou serviços.

Segundo Anslinger e Jenk (2004), o insucesso das alianças estratégicas ocorre devido ao fato de as empresas não adotarem formas de avaliar o real desempenho organizacional. A forma mais propícia para mensurar isso é definir poucos objetivos-chave e estabelecer um conjunto de métricas para auxiliar a parceria e alcançar os propósitos pré-estabelecidos. Para 
Prahalad e Hamel (1995), o êxito das alianças ocorre quando há alinhamento e singularidade das competências entre parceiros.

\subsection{Modelo de qualidade em serviços}

O modelo de qualidade em serviços de Kano (1984), mostrado na figura 1, auxilia na melhor compreensão da relação entre as atitudes do cliente frente ao serviço e o tipo de requisito associado ao desempenho desse serviço. O modelo está focado em três tipos de qualidade: a básica, a de desempenho e a de excitação. O primeiro geralmente não é verbalizado pelos clientes, pois estes já esperam que a qualidade básica esteja contemplada no serviço - caso contrário, a insatisfação será gerada. O segundo é verbalizado pelo cliente e a satisfação é proporcional ao grau de desempenho: quanto maior esse grau, maior será a satisfação do cliente. Já o terceiro tipo de qualidade é aquele não verbalizado, pois proporciona benefícios que os clientes não esperavam, tornando-se o principal para geração de valor. Este é o modelo usado para posicionar estrategicamente o Centro Universitário Católico de Santa Catarina em relação à qualidade dos serviços prestados.

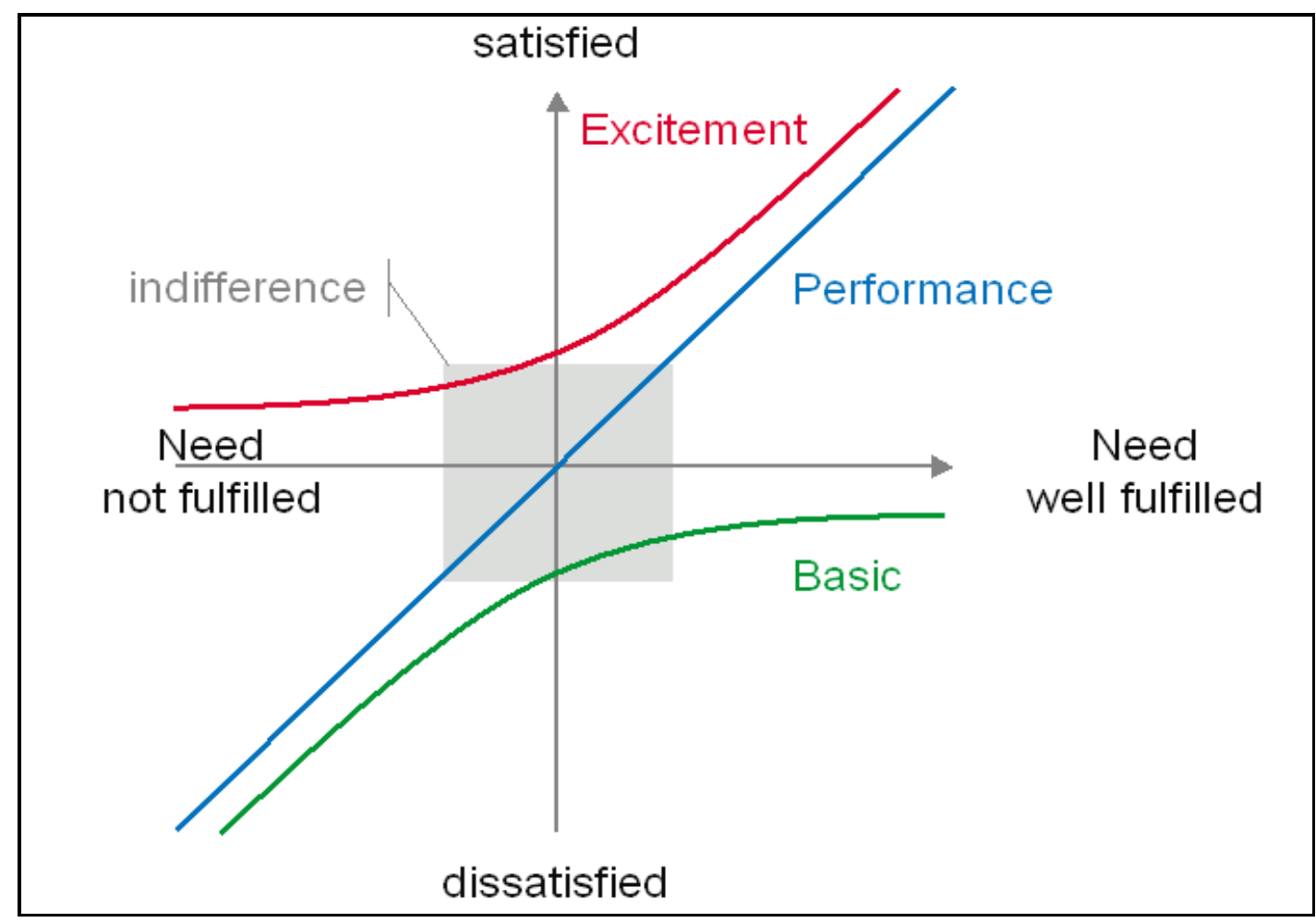

Figura 1 Modelo de qualidade em serviços

Fonte: Kano (1984). 


\section{DESENVOLVIMENTO METODOLÓGICO}

Segundo Faria (2008), o paper, position paper ou artigo de posicionamento é um pequeno artigo científico a respeito de um determinado assunto, caracterizado pela originalidade e destinado a marcar a posição dos pesquisadores. Na elaboração de um paper, o autor irá desenvolver análises e argumentações, com objetividade e clareza, podendo considerar, também, opiniões de especialistas.

Segundo Heerdt e Leonel (2006), o position paper é produzido para divulgar resultados de pesquisas científicas. Entretanto, esse tipo de trabalho também pode ser elaborado com a intenção de discutir aspectos de assuntos ainda pouco estudados ou ainda não estudados.

Segundo Faria (2008), o position paper normalmente reflete a experiência dos pesquisadores sobre o que está ocorrendo em seu campo de pesquisa, objetivando reunir de forma organizada as informações e, ao fazê-lo, provocar uma rediscussão do assunto, colher sugestões e, possivelmente, encaminhar sugestões ou até mesmo propor soluções. Nesse sentido, o position paper visa incentivar o exercício e o desenvolvimento da capacidade crítica e analítica, além de propiciar a prática da linguagem científica. Esse tipo de trabalho objetiva avaliar a capacidade dos pesquisadores em expressar o entendimento do tema em discussão.

Segundo Heerdt e Leonel (2006, p. 143), o position paper consiste no desenvolvimento da

capacidade de reflexão e criatividade [do aluno] diante do que está escrito (livro, artigo, revista, jornal, etc.), diante do que é apresentado (palestra, congresso, seminário, curso, etc.) e também diante do que pode ser observado numa determinada realidade (empresa, projeto, entidade, viagem de estudos, etc.).

Portanto, para Heerdt e Leonel (2005, p. 144), a composição de um paper decorre do posicionamento de quem o escreve, exigindo do autor, também, a revisão de literatura para que este conheça e seja capaz de sistematizar o posicionamento de outros autores sobre o tema em questão. 


\section{O POSICIONAMENTO ESTRATÉGICO DO CENTRO UNIVERSITÁRIO CATÓLICO DE SANTA CATARINA}

O Centro Universitário Católico de Santa Catarina tem seu posicionamento estratégico focado em uma associação entre excelência de ensino e diversidade de cursos. Dentro de uma divisão clássica entre instituições premium e instituições de conveniência, ele busca se posicionar no primeiro grupo. Com isso, abandonam-se as estratégias de competição por preço e os diferenciais de conveniência, em que a facilidade de acesso é o fator preponderante.

No grupo das instituições premium, no que se refere ao número de cursos e à diversidade de áreas do conhecimento, existem as instituições de nicho, com um pequeno número de cursos, normalmente dentro de uma mesma área do conhecimento, como o ITA, de São José dos Camposque é um exemplo clássico de instituição com foco nas engenharias. Já as instituições premium de abrangência, como algumas universidades, tentam olhar o conhecimento de forma universal,como o próprio termo sugere, tendo muitos cursos distribuídos em diversas áreas de conhecimento.

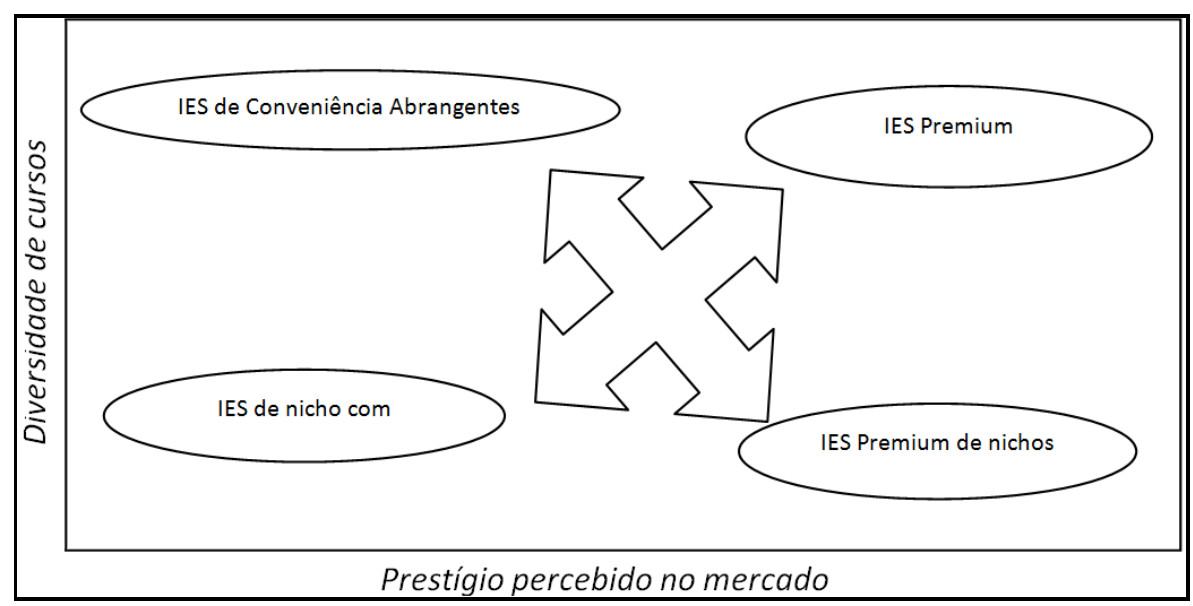

Figura 2 Conjunto de estratégias

Fonte: Adaptado de Mintzberg e Quinn (2001).

As estratégias foram definidas como um subconjunto do conjunto de estratégias derivadas dos conceitos preconizados por Mintzberg (2001). Esse conjunto é apresentado na figura 2. A escolha das estratégias foi traduzida como uma sequência lógica - ContextoEstratégia-Estrutura -, caracterizando assim uma filosofia de trabalho do tipo "market driven". Para a implantação do projeto do Centro Universitário Católico de Santa Catarina, foi escolhido um conjunto de duas estratégias principais descritas no referencial teórico. Esse 
conjunto de estratégias foi concebido de forma integrada e colocado em prática adotando-se uma estratégia mais tradicional e outra mais inovadora.

\subsection{Estratégia de excelência nos serviços acadêmicos e de suporte}

Muitos trabalhos acadêmicos foram publicados, em especial nos anos 1990, enfatizando a importância e a complementaridade de dois tipos de qualidade: a intrínseca e a percebida pelos clientes. A qualidade intrínseca é primordialmente quantitativa e pode ser medida de forma mais objetiva por meio de parâmetros técnicos, com medições diretas e instrumentos passíveis de aferição. Já a qualidade percebida é primordialmente qualitativa, e a satisfação dos envolvidos é normalmente medida por instrumentos indiretos, como a escala de Lickert.

Em um projeto direcionado para o mercado em um ambiente de crescente competição, cumprir as exigências do MEC é um fator crítico. Contudo, a qualidade percebida pelos alunos e professores não é, necessariamente, proporcional à instrínseca e não pode ser negligenciada. Como um exemplo da aplicação desse conceito, podemos usar o diagrama de Kano (1984), apresentado na figura 1. O autor descreve três tipos de qualidade: a básica, a de desempenho e a de excitação.

A qualidade básica é composta por requisitos que têm como principal característica a insatisfação quando esse requisito não corresponde à expectativa. Para a reforma da Unidade de Joinville, fez-se uma lista desses requisitos, e o mobiliário - em especial as cadeiras e o estacionamento - foram os mais citados. Tais itens não são definidores da opção pela instituição; contudo, lideram no ranking de reclamações.

A qualidade de desempenho, apresentada por uma diagonal no diagrama, tem como exemplo principal a qualidade percebida pelos alunos com relação ao corpo docente. Foi percebido que, para os cursos de especialização, por exemplo, itens como a titulação, que demonstram a qualidade intrínseca de um professor, não estão necessariamente vinculados à qualidade percebida pelo aluno.

A qualidade de excitação é influenciada por requisitos cuja inexistência não causa nenhum grau de insatisfação nos alunos, porém, quando são colocados em prática, geram um aumento significativo no grau de satisfação. 
Um trabalho matricial, destacando os requisitos dos três tipos de qualidade apresentados, gerou uma lista de itens com enfoque gerencial para o acompanhamento da operação, analisando os requisitos de qualidade intrínseca e percebida.

\subsection{Estratégia de coopetição com instituições comunitárias da região}

Desde a implementação do Instituto Católico de Santa Catarina, em agosto de 2009, este buscou uma parceria com as outras IES locais. A formalização de um acordo de cooperação entre as três IES comunitárias de Joinville - o Instituto Católico, a Univille e o Bom Jesus Ielusc - deu inicio à concretização de ações dentro dessa cooperação.

A inauguração, no final de 2010, do Inovaparque, único parque tecnológico no Brasil de cuja gestão participam quatro IES - Univille, UFSC, UDESC e Católica de SC -, representa um ícone do esforço de cooperação executado pelas instituições.

\section{CONSIDERAÇÕES FINAIS}

Diante do aumento da competição por parte de grandes grupos econômicos no setor da educação, o ganho de escala por meio de ações de cooperação e de coopetição por parte das pequenas e médias instituições se apresenta como o caminho mais viável no momento para o crescimento e, em alguns casos, a sobrevivência no setor de ensino superior privado. Embora a presença de grandes grupos privados seja menor no Estado de Santa Catarina com relação a vários outros estados da Federação, a tendência é que esse movimento, que já se consolidou no Estado do Rio Grande do Sul, em 2011, caminhe gradativamente também para o Estado de Santa Catarina, aumentando a necessidade de coopetição como uma das principais estratégias possíveis de sobrevivência, crescimento e desempenho.

\section{REFERÊNCIAS}

AGOSTINHO, M. E. Complexidade e organizações: em busca da gestão autônoma. Rio de Janeiro: Atlas, 2003.

ANDREWS, K. R. The concept of corporate strategy. In: MCKIERNAN, Peter (Ed.).

Historical evolution of strategic management. Vol. I. Brookfield: Darmouth, 1996. p. 1544.

ANSLINGER, P.; JENK, J. Creating successful alliances. Journal of Business Strategy, v. 25, n. 2, p. 18-22, 2004. 
BARNEY, J. Firm resources and sustained competitive advantage. Journal of Management, 17, p. 99-120, 1991.

BENGTSSON, M.; KOCK, S. Cooperation and competition in relationships between competitors in business networks. The Journal of Business \& Industrial Marketing. v. 14, n. 3, p. 178-194, 1999.

BOURDIEU, P. Razões práticas: sobre a teoria da ação. Campinas: Papirus, 1996.

DAGNINO, G. B.; PADULA, G. Coopetition strategy: a new kind of interfirm dynamics for value creation. In: THE EUROPEAN ACADEMY OF MANAGEMENT SECOND ANNUAL CONFERENCE, 2, 2002, Estocolmo. Anais... Estocolmo: Innovative Research in Management, 2002. Disponível em:

$<$ http://www.altruists.org/static/files/CoOpetition\%20Strategy.pdf $>$. Acesso em: 10 out. 2007.

DOTTO, Dalva M. R.; WITTMANN, Milton L. Coopetição. In: SIEDENBERG, Dieter R. (Coord.). Dicionário do desenvolvimento regional. Santa Cruz do Sul: EDUNISC, 2006.

FARIA, S. E. "Paper - o que é e como fazer". Artigo publicado no site Copyleft da Pearson Education em 17 de Junho de 2008. Disponível em:

$<$ http://www.copyleftpearson.com.br/artigo_detalhe_logado.aspx?id=54>. Acesso em: 17 out. 2011.

GOLLO, S. S. Framework para análise das inovações e das estratégias de cooperação competitiva - coopetição: estudo de caso da indicação de procedência Vale dos Vinhedos Serra Gaúcha/RS. In: XXX ENANPAD, Salvador-BA, 2006. Disponível em: $<$ http://www.anpad.org.br/>, acesso restrito. Acesso em: 12 out. 2011.

GOMEZ, M. A Bourdieusian perspective on strategizing. In: GOLSORKHI, D. et al. Cambridge handbook of strategy as practice. Cambridge: Cambridge University Press, 2010.

GRAY, B.; WOOD, D. J. Toward a comprehensive theory of collaboration. Journal of Applied Behavioral Science, v. 27, n. 2, p. 139-162, 1991.

HAMEL, Gary. Competition for competence and Inter-Partner Learning within International Strategic Alliances. Strategic Management Journal, v. 12, p. 83-103, 1991.

HEERDT, M. L.; LEONEL, V. Metodologia científica e da pesquisa: livro didático. 4. ed. Palhoça: UnisulVirtual, 2006.

HITT, M. A.; IRELAND R. D.; HOSKISSON, R. E. Administração estratégica: competitividade e globalização. São Paulo: Pioneira Thomson Learning, 2002.

HOPER GROUP. Panorama do ensino superior privado e dos maiores grupos educacionais do Brasil. 2010a.

Sobrevivendo aos consolidadores. 2010b. 
INEP. Censo da educação superior: resumo técnico. Distrito Federal: Ministério da Educação, 2009.

KANO, N. et al. Attractive quality and must-be quality. Hinshitsu, v. 4, n. 2, p. 147-56, 1984.

KANTER, R. M. Classe mundial. Rio de Janeiro: Campus, 1996.

LADO, A.; BOYD, N. G.; HANLON, S. C. Competition, cooperation, and the search for economic rents: a syncretic model. Academy of Management Review, v. 22, p.110-141, 1997.

LEÃO, D. A. F. S. Relevância da teoria da coopetição para a compreensão da dinâmica dos relacionamentos entre empresas concorrentes. In: II Encontro de Estudos em Estratégia, ANPAD, Rio de Janeiro-RJ, 2005. Disponível em: <http://www.anpad.org.br/>, acesso restrito. Acesso em: 11 out. 2011.

LENGLER, L.; RATHMANN, R. Assimetria de relacionamentos na cadeia apícola do Rio Grande do Sul. Revista da FAE, v. 9, p. 51-63, 2006.

MARTINELLI, E.; SPARKS, L. Food retailers and financial services in the UK: a cooperative perspective. British Food Journal, v. 105, n. 9, 2003.

MEROFA, A.; BUENO, C. F. Coopetição: uma análise teórica. In: IV ENCONTRO DE ESTUDOS EM ESTRATÉGIA, Recife-PE, 2009. Disponível em:

$<$ http://www.anpad.org.br/>, acesso restrito. Acesso em: 12 out. 2011.

MINTZBERG, H.; QUINN, J. B. O processo de estratégia. 3. ed. Porto Alegre: Bookman, 2001 .

MINTZBERG, H.; WATERS, J. A. Of strategies, deliberate and emergent. Strategic Management Journal, v. 6, n. 3, p. 257-272, 1996.

MINTZBERG, Henry; AHLSTRAND Bruce; LAMPEL Joseph. Safári de estratégia: um roteiro pela selva do planejamento estratégico. Trad. de Nivaldo Montingelli Jr. Porto Alegre: Bookman, 2000.

NALEBUFF, B. J.; BRANDENBURGER, A. M. Co-opetição: um conceito revolucionário que combina competição com cooperação e a estratégia da Teoria do Jogo que está mudando o jogo dos negócios. Rio de Janeiro: Rocco, 1996.

PORTER, M. E. Competição: estratégias competitivas essenciais. Rio de Janeiro: Campus, 1999.

PRAHALAD, C. K.; HAMEL, G. Competindo pelo futuro. Rio de Janeiro: Campus, 1996.

QUINT, B. Coopetition: sleeping with the enemy. Information Today, v. 14, n. 1, p. 7, jan. 1997. 
SECRETARIA DE ESTADO DA EDUCAÇÃO. Censo-Escolar, 2010. Disponível em: $<$ http://www.sed.sc.gov.br/secretaria/censo-escolar>. Acesso em: 27 out. 2011.

VERSCHOORE, J. R. F.; BALESTRIN, A. Fatores competitivos das empresas em redes de cooperação. In: XXX ENANPAD, Salvador-BA, 2006. Disponível em:

$<$ http://www.anpad.org.br/>, acesso restrito. Acesso em: 12 out. 2011. 